ERNEST

BERKELEY NATIDNAL LABGRATURY $45 \div 3$

Impacts of Cool Cities on Air Quality: A Preliminary Modeling Assessment for Nashville, TN, Dallas, TX and Atlanta, GA

Haider Taha

Environmental Energy

Technologies Division

September 1998
ARCEIVED

APR 131999

OSTI 


\section{DISCLAIMER}

This document was prepared as an account of work sponsored by the United States Government. While this document is believed to contain correct information, neither the United States Government nor any agency thereof, nor The Regents of the University of California, nor any of their employees, makes any warranty, express or implied, or assumes any legal responsibility for the accuracy, completeness, or usefulness of any information, apparatus, product, or process disclosed, or represents that its use would not infringe privately owned rights. Reference herein to any specific commercial product, process, or service by its trade name, trademark, manufacturer, or otherwise, does not necessarily constitute or imply its endorsement, recommendation, or favoring by the United States Government or any agency thereof, or The Regents of the University of California. The views and opinions of authors expressed herein do not necessarily state or reflect those of the United States Government or any agency thereof, or The Regents of the University of California.

This report has been reproduced directly from the best available copy.

Available to DOE and DOE Contractors

from the Office of Scientific and Technical Information

P.O. Box 62, Oak Ridge, TN 37831

Prices available from (615) $576-8401$

Available to the public from the National Technical Information Service

U.S. Department of Commerce

5285 Port Royal Road, Springfield, VA 22161

Ernest Orlando Lawrence Berkeley National Laboratory is an equal opportunity employer. 


\section{DISCLAIMER}

Portions of this document may be illegible in electronic image products. Images are produced from the best available original document. 
LBNL-42256

\title{
Impacts of Cool Cities on Air Quality: A Preliminary Modeling Assessment for Nashville, TN, Dallas, TX and Atlanta, GA
}

\author{
Haider Taha \\ Heat Island Group \\ Environmental Energy Technologies Division \\ Lawrence Berkeley National Laboratory \\ Berkeley, CA 94720 \\ http://EETD.LBL.gov/HeatIsland
}

September 1998 


\begin{abstract}
Previous atmospheric modeling efforts that concentrated on the Los Angeles Basin suggested beneficial and significant air quality impacts from cool cities strategies. This paper discusses an extension of similar modeling efforts to three regions, Atlanta GA, Dallas - Ft. Worth TX, and Nashville TN, that experience smog and air quality problems. According to the older ozone air quality standard (120 ppb), these regions were classified as serious, moderate, and marginal, respectively, but may be out of compliance with respect to the newer, 80 -ppb/8-hours standard.
\end{abstract}

Results from this exploratory modeling work suggest a range of possible impacts on meteorological and air quality conditions. For example, peak ozone concentrations during each region's respective episode could be decreased by 1-6 ppb (conservative and optimistic scenarios, respectively) in Nashville, 5-15 ppb in Dallas - Fort Worth, and 5-12 ppb in Atlanta following implementation of cool cities. The reductions are generally smaller than those obtained from simulating the Los Angeles Basin but are still significant. In all regions, the simulations suggest, the net, domain-wide effects of cool cities are reductions in ozone mass and improvements in air quality. In Atlanta, Nashville, and Dallas, urban areas benefiting from reduced smog reach up to 8460,7350 , and $12870 \mathrm{~km}^{2}$ in area, respectively.

Results presented in this paper should be taken as exploratory and preliminary. These will most likely change during a more comprehensive modeling study to be started soon with the support of the US Environmental Protection Agency. The main purpose of the present project was to obtain the initial data (emission inventories) for these regions, simulate meteorological conditions, and perform preliminary sensitivity analysis. In the future, additional regions will be simulated to assess the potential of cool cities in improving urban air quality.

\title{
BACKGROUND
}

It is expected that cool cities (high-albedo materials and urban reforestation) strategies will be implemented particularly in warm and hot climates of the U.S. This will likely happen if these measures are adopted in building energy codes and urban planning regulations as well as air quality management plans (e.g., State Implementation Plans, SIPs). The implementation of these strategies is expected to lead to reduction of air temperature in urbanized regions. Resulting benefits include decreased energy use, reduced pollutant emissions, and improved air quality. Field-measurements and modeling studies have corroborated 
these expectations. For example, Gabersek and Taha (1996), Taha et al. (1997a,b), Taha $(1996,1997)$, and Sailor (1993) show that implementing cool cities strategies may be an effective way of reducing urban air temperatures by up to $5^{\circ} \mathrm{C}$ in summer and, correspondingly, improve air quality by $10-20 \%$ (that is reducing exceedance exposure to ozone by 10-20\%). Other studies demonstrated and quantified the potential savings in cooling energy use due to cool cities strategies (e.g., Akbari et al. 1994, Parker and Barkaszi 1994, Simpson and McPherson 1993). These studies suggested net energy savings in residential and commercial buildings in the range of 5-15\%. In some situations, e.g., specific homes, residential cooling energy savings attained $100 \%$ whereas in other cases, they were minimal. But overall, the savings are quite significant. Based on these and related findings, it is now being suggested that U.S. cities in warm and hot climates gradually implement the large-scale use of high-albedo materials and urban forests to lower surface and air temperatures, save energy, and improve air quality.

The general consequences of lower ambient temperatures include 1) a decrease in some photochemical reaction rates, 2) a decrease in temperature-dependent biogenic hydrocarbon emissions, 3) a decrease in evaporative losses of organic compounds from mobile and stationary sources, and 4) a decreased need for cooling energy, generating capacity, and, ultimately, emissions from power plants. Thus in this sense, cool cities have a potential for reducing ozone formation. However, decreasing the near-surface temperatures can also decrease the depth of the mixed layer at some locations in the airshed, potentially trapping pollutants (in a shallower boundary layer), possibly resulting in higher ozone concentrations. Decreasing nearsurface temperatures may also weaken the local circulation (e.g., sea or land breezes) which can cause a small increase in ozone concentrations in upper layers of the atmosphere (Taha 1997).

With lower air temperatures, lower ozone concentrations can generally be expected. The most important mechanism through which air temperature affects ozone production is believed to be the chemistry of peroxyacetyl nitrate, PAN (Cardelino and Chameides 1990). In sensitivity simulations of the Los Angeles Basin, Taha et al. (1994) showed that if only the airshed's temperature were decreased, that would always result in decreasing ozone concentrations. For example, an average decrease of $12 \%$ resulted when domain-wide average temperature was decreased by $1.5^{\circ} \mathrm{C}$. However, when temperatures are lower, the depth of the mixed layer can be relatively shallower, as mentioned above. This can potentially increase local concentrations or increase ozone scavenging at other times, i.e., when NO is not completely titrated. Thus there is a balancing act and the net effects must be carefully quantified through meteorological and photochemical modeling.

During the past five years, the Los Angeles Basin was the target of modeling studies that assessed the ef- 
fectiveness of cool cities in reducing atmospheric temperatures and slowing the production of photochemical smog (e.g., Taha 1996,1997, Tran and Mirabella 1997). These studies came up with the similar conclusion that cool cities can have significant beneficial effects in the Los Angeles region. For example, peak ozone concentrations were decreased by $40 \mathrm{ppb}$ or more as a result of peak temperature reductions of up to $4.5^{\circ} \mathrm{C}$. With large increases in albedo, the peak concentration at 3 PM decreased by up to $7 \%$ (from 220 down to $205 \mathrm{ppb}$ ) while the total ozone mass in the mixed layer decreased by up to 640 metric tons (a decrease of 4.7\%). With respect to the older National Ambient Air Quality Standard, domain-wide population-weighted exceedance exposure to ozone decreased by up to $16 \%$ during peak afternoon hours (Taha 1996,1997).

This paper presents results from an exploratory study that is an extension of the Los Angeles modeling study to other regions in the U.S. The paper summarizes preliminary results to assess the impacts of cool cities in Nashville TN, Dallas - Ft. Worth TX, and Atlanta GA. In the near future, other US regions will be simulated, too, to develop a better assessment of the potential benefits of cool cities.

Several institutions are interested in assessing the potential air quality impacts of cool cities in various regions of the U.S., e.g., EPA and DOE, as well as local Air Quality Management Districts, e.g., the South Coast Air Quality Management District, the Bay Area Air Quality Management District, and the Georgia Department of Natural Resources. The purpose of the present project was to initiate this activity by obtaining emission inventories and data, and performing preliminary meteorological and photochemical simulations to pave the way for more in-depth and comprehensive modeling to start in FY 1998. The simulations are exploratory in the sense that they are the first such for these regions and that they are preliminary, i.e., based on preliminary assumptions, scenarios, and data. Modifications to the Urban Airshed Model's input was done in a simplistic manner, as described later, since no emissions pre-processing systems were available for the study regions. That precludes the possibility of formulating more concise conclusions at this time. A more comprehensive study of these and other regions will be undertaken in the very near future, and these deficiencies will be corrected.

\section{APPROACH}

\section{General modeling approach}

The general approach followed in this study has been described in detail in Taha $(1996,1997)$ and will on- 
ly very briefly be mentioned here. It involves performing a set of mesoscale meteorological simulations to establish episodic, base- and modified-scenario (i.e., cool cities) conditions for each region. The meteorological modeling episodes were selected to coincide with the State Implementation Plan episodes designated by the respective air pollution control district or air quality planning agency for each region. For Dallas and Nashville, the length of the simulation episode was 2 days, whereas for Atlanta, it was 4 days. Meteorological simulations were initialized with soundings data from the National Weather Service and the National Oceanic and Atmospheric Administration (NOAA). Cool-cities scenarios were simulated (for increased albedo, vegetation fraction, or both) based on modified land-use/land-cover data. The original (i.e., base-case) land-use/land-cover data were based on USGS 200-m classification. Following establishment of meteorological base and modified scenarios for each region and episode, differences in timedependent, three dimensional meteorological prognostic variables (e.g., air temperature, wind, and moisture fields) were quantified and stored in four-dimensional $(\mathrm{x}, \mathrm{y}, \mathrm{z}, \mathrm{t})$ arrays.

A photochemical base-case scenario was established using UAM-ready (Urban Airshed Model) input data (meteorology and emissions) for each region respectively. The modified photochemical scenarios were then simulated using modified UAM input obtained by applying the four-dimensional difference arrays to each respective parameter.

The meteorological impacts of cool cities were simulated with the Colorado State University Mesoscale Model (CSUMM) whereas the air quality impacts were simulated with the UAM. The CSUMM is a hydrostatic, primitive-equation, three-dimensional Eulerian model originally developed by Pielke (1974). The model is incompressible, and employs a $\sigma_{\mathrm{z}}$ coordinate system. It uses a first order closure scheme in treating sub-grid scale terms of the governing differential equations. The model's domain is about $10 \mathrm{~km}$ high with an underlying soil layer about $50 \mathrm{~cm}$ deep. In this study, 22 atmospheric computational levels were used. The CSUMM generates three-dimensional fields of prognostic variables as well as a mixing height field that can be used as input to the UAM.

The UAM is a three-dimensional, Eulerian, photochemical model capable of treating inert and chemically-reactive atmospheric pollutants. It has been recommended by the EPA for ozone air quality modeling studies of urban areas (EPA 1986). The UAM simulates the advection, diffusion, transformation, emission, and deposition of pollutants. It treats about 30 chemical species and uses the carbon bond CB-IV mechanism (Gery et al. 1988). The UAM accounts for emissions from area and point sources, elevated stacks, mobile and stationary sources, and vegetation (biogenic emissions). In this study, the UAM was run with 5 atmospheric layers of variable depth and the top of the domain was set at $2540 \mathrm{~m}$ for Nashville, 
$2700 \mathrm{~m}$ for Dallas, and $2200 \mathrm{~m}$ for the Atlanta modeling domains.

Combined, the CSUMM and UAM solve a set of coupled, non-linear partial differential equations describing the time-dependent prognostic meteorological fields and pollutant species concentrations. These equations represent conservation of mass (continuity), potential temperature (heat), momentum, water vapor, and chemical species continuity, respectively.

Unlike past cool cities modeling work by Taha $(1996,1997)$ which used a three-dimensional version of UAM (UAM IV-5.52), this study uses the regulatory version (UAM IV-6.20) because SIP input files obtained from AQMDs were prepared specifically for this version. A major difference between the two versions is that UAM-5.52 imports three-dimensional meteorological fields from the mesoscale model (e.g., CSUMM), whereas version 6.20 imports only the surface, 2-dimensional fields and internally computes their vertical distribution. Another difference of relevance to cool cities (i.e., temperature decrease) is that of PAN chemistry, which is most responsible for ozone formation through the production of nitrogen dioxide. The specific UAM equations for PAN chemistry have different rate constants and different temperature factors (dependence) in versions 6.20 and 5.52. The implication of these differences is that the PAN chemistry, and thus ozone production, is more sensitive to temperature in version 6.20 than in 5.52 .

In the preliminary modeling work discussed here, there was insufficient data to perform the modeling tasks at the desired level of accuracy. For example, land-use data and land-water boundaries information were not available for Nashville TN. Also, emission pre-processors were not available for all three study regions and, thus, emission inventories were not modified in a proper manner to account for cool cities. In the proposed FY 98 modeling work to be supported by the US EPA, these deficiencies will be corrected and data will be obtained directly from air pollution control agencies participating in this project.

\section{UAM input modification approach}

Because of lack of pre-processors that are specific to the study regions, complete pre-processing and regeneration of meteorological and air emission input (i.e., initial and boundary conditions) to the UAM as was done in Taha $(1996,1997)$ was not feasible. Instead, a simplistic method was developed here to "paste" differences in these fields onto existing SIP UAM input files. As mentioned earlier, fourdimensional difference arrays were applied to base-case UAM input to generate the modified scenario input. Dynamic consistency is ensured by using fields produced in the mesoscale meteorological model as 
they are consistent, i.e., temperature, winds, mixing height, and atmospheric moisture. Of course, this approach inherently assumes that the original (SIP) input to the UAM is itself dynamically consistent, which may or may not be the case. This approach is probably not the most appropriate, due to the deficiencies noted above, but was adopted due to lack of information and tools in this preliminary study. The needed tools will be acquired in a following EPA-sponsored project.

The UAM-ready (base-case) meteorological and emissions inputs for each region were obtained from the respective air pollution control district or air quality planning agencies. For the three regions under study, the data were obtained from Tennessee Valley Authority, the Georgia Department of Natural Resources, and the Texas Natural Resource Conservation Commission.

To provide a range of possible impacts, various meteorological implications of cool cities were tested with the Urban Airshed Model using sets of four-dimensional difference arrays as mentioned above. Specifically, various levels of changes in air temperature, changes in the duration of cool cities effects (day, night and day), various levels of mixing height changes (decreases), area affected by meteorological changes from cool cities, changes in VOC emissions resulting from changes in air temperature, and combinations of these aforementioned effects were tested. In the "Results" section, in addition to a base case scenario for each region, two cases are reported to present the possible range of effects. One is labeled "conservative", the other "optimistic". As implied, the first assumes small modifications in and effects of surface properties changes, e.g., surface albedo or vegetation fraction increases, whereas the second assumes a larger level of surface properties changes. A word of warning here is that the scenarios developed so far are crude and far from accurate.

In the context of the three regions modeled here, the conservative scenario is roughly equivalent to a maximum daytime temperature reduction on the order of $0.5^{\circ} \mathrm{C}$, a negligible change in the mixing height, no nighttime effects of surface modifications, small affected urban area, and no changes in emissions of NOx or VOC. In the optimistic scenario, on the other hand, the maximum daytime temperature decrease is on the order of $3-4^{\circ} \mathrm{C}$, the effect of surface modifications extends through the night, the decrease in the mixing height is on the order of $20-30 \%$ over urban areas, the area affected by surface modifications is roughly doubled, and the emission of biogenic VOC is reduced by up to $20 \%$ (as a result of temperature decrease). 


\section{UAM MODELING DOMAINS AND EPISODES}

The UAM modeling domains, i.e., both their horizontal and vertical extents, and mesh sizes used in this study were adopted from the respective sources of the emission inventories, i.e., air quality management districts in Tennessee, Texas, and Georgia. On the other hand, the CSUMM. modeling domains were selected to be much larger (roughly ten times larger) than the corresponding UAM domains and are much more varied in topography and land cover.

For Nashville, the UAM modeling domain is in UTM zone 16 and is $230 \times 200 \mathrm{~km}$ (46 cells in the E-W direction and 40 cells in the N-S direction). The mesh size is $5 \times 5 \mathrm{~km}$. The Dallas-Ft. Worth TX domain is $200 \times 170 \mathrm{~km}$ ( 40 cells in the E-W direction and 34 cells in the N-S direction). Again, the mesh size is $5 \times 5 \mathrm{~km}$ and the modeling domain is in UTM zone 14. For Atlanta GA, the domain is $160 \times 160 \mathrm{~km}(40$ cells in the N-S and E-W directions) and the mesh size is $4 \times 4 \mathrm{~km}$. The Atlanta modeling domain is in UTM zone 16. All three UAM modeling domains are roughly flat with no major topographical features or major water bodies. Shallow terrain slopes are seen as well as relatively small water bodies (e.g., small lakes, rivers, and reservoirs). The modeling episodes are June 23 and 24 (1988) for Nashville TN, June 17 and 18 (1987) for Dallas-Fort Worth TX, and July 29 through August 1 (1987).

\section{SIMULATION RESULTS}

Since this modeling work is exploratory, the paper does not present one specific set of impacts from implementation of cool cities; rather, a "conservative" and an "optimistic" scenario will be used for each region to loosely delineate a range of impacts. The reason for doing so is that the modeling/data uncertainties at this stage of the study preclude drawing a precise or final conclusion. While the conservative estimates are meant to be just that, conservative assessments of the (smallest) impacts, the optimistic scenario is meant to show that larger impacts may be achieved. This is particularly true if model input is improved, emission inventories reprocessed, and canopy layer mechanisms (not boundary layer) are accounted for. With such a combination of factors, the simulated effects of cool cities can be larger, thus the optimistic scenario. And, as mentioned elsewhere in this report, the preliminary results will certainly change once the deficiencies in the present approach are corrected and more appropriate input data developed or obtained.

For clarity and consistency, results are presented for the peak ozone hour on the last day of the modeling 
episode for each region, respectively. That corresponds to $5 \mathrm{pm}$ on June 24 (day 2 of episode) in Nashville TN, 5 pm on August 1st (day 4 of episode) in Atlanta GA, and 4 pm on June 18 (day 2 of episode) in Dallas - Ft. Worth TX. These respective times will be referred to as "peak hour" in the following discussion. It should be borne in mind, however, that the largest (most beneficial) impacts of cool cities (as simulated in this study) do not necessarily occur at that peak hour. In fact, the simulations suggest, they tend to occur earlier than, and sometimes after, the peak hour.

\section{Air quality impacts in Nashville TN.}

Figure 1 shows the simulated base-case ozone concentrations at peak hour in the Nashville region. The range is 12 to $106 \mathrm{ppb}$ over the modeling domain. There is clearly no violation with respect to the older standard $(120 \mathrm{ppb})$ but not so with respect to the newer one $(80 \mathrm{ppb})$. The location of the highest concentration is to the northeast of Nashville's center (at cell 31,39). During this peak hour, $43 \%$ of the domain is out of compliance with respect to $80 \mathrm{ppb}\left(722\right.$ grid cells, or $\left.18050 \mathrm{~km}^{2}\right)$.

In the conservative case, shown in Figure 2, ozone concentrations are both increased and decreased (with respect to the base case) as a result of cool cities. The largest decrease is on the order of $1 \mathrm{ppb}$, whereas the largest increase on the order of $2 \mathrm{ppb}$. Both are negligible. In the optimistic scenario (Figure 3 ), the largest increase is about $5 \mathrm{ppb}$ whereas the largest decrease is about $6 \mathrm{ppb}$. However, the area affected by decreasing concentrations is larger than that affected by increased ones and the net effect is a reduction in overall concentrations. In this case, there are 58 cells with increased concentrations compared to 294 cells with decreased ozone. With respect to the $80-\mathrm{ppb}$ threshold, the optimistic scenario has 706 cells above the standard, down from 722 in the base case.

The simulations also suggest that the highest concentration (at cell 31,39) is unchanged by surface modification (cool cities) scenarios. Instead, other locations in the domain benefit from the surface modifications. Table 1 summarizes some other air quality attributes for Nashville TN (and the other two regions as well).

Air quality impacts in Dallas-Ft. Worth TX.

Figure 4 shows the simulated base-case ozone concentrations at peak hour in the Dallas - Ft. Worth re- 
gion. The concentrations range from 20 to $93 \mathrm{ppb}$ over the modeling domain. As in the case with Nashville, the simulated episode for Dallas suggests no violation with respect to the $120 \mathrm{ppb}$ threshold but some non-compliance with respect to the new standard of $80 \mathrm{ppb}$. The location of the highest concentration is to the southeast of Dallas (at location 30,8). During this peak hour, $4 \%$ of the domain is out of compliance with respect to $80 \mathrm{ppb}$ (44 grid cells, or $1100 \mathrm{~km}^{2}$ ).

In the conservative case, shown in Figure 5, the concentrations are both increased and decreased following implementation of cool cities. The largest decrease is on the order of $5 \mathrm{ppb}$, whereas the largest increase on the order of $1 \mathrm{ppb}$. In the optimistic scenario (Figure 6) on the other hand, the largest increase is about $4 \mathrm{ppb}$ whereas the largest decrease is about $15 \mathrm{ppb}$. Also, the area affected by decreasing concentrations is larger than that affected by increased ones. In this case, there are 92 cells with increased concentrations compared to 515 cells with decreased ozone. With respect to the 80 -ppb threshold, the optimistic scenario has 27 cells above the standard (compared to 44 in the base case).

With respect to the old standard of $120 \mathrm{ppb}$, the modeling of this episode suggests that Dallas is in compliance. The simulations also suggest that the highest concentration (at location 30,8 ) is decreased by a modest amount $(3 \mathrm{ppb})$ in the optimistic scenario. Also refer to Table 1 for other attributes.

\section{Air quality impacts in Atlanta GA.}

Figure 7 shows the simulated base-case ozone at peak hour in the Atlanta GA region. The concentrations range is relatively higher than the corresponding ones in the two regions discussed earlier. In Atlanta, ozone ranges from 40 to $140 \mathrm{ppb}$ over the modeling domain thus violating both the older and newer ozone air quality standards during the simulation episode. The highest concentration is located slightly to the northeast of urban Atlanta, at grid cell $(29,21)$. At this peak hour, $72 \%$ of the domain is out of compliance

with respect to $80 \mathrm{ppb}$ (1043 grid cells, or $16600 \mathrm{~km}^{2}$ ) and $10 \%$ is out of compliance with respect to the older standard (145 cells or $2320 \mathrm{~km}^{2}$ ).

In the conservative case, shown in Figure 8, the largest decrease is on the order of $5 \mathrm{ppb}$, and the largest increase on the order of $3 \mathrm{ppb}$. In the optimistic scenario (Figure 9) on the other hand, the largest increase is about $6 \mathrm{ppb}$ whereas the largest decrease is about $12 \mathrm{ppb}$. As in the other two regions, the area affected by decreasing concentrations is larger than that affected by increased ones and the net effect is a reduction in overall concentrations. There are 95 cells with increased concentrations compared to 529 cells with de- 
creased ozone. With respect to the 80-ppb threshold, the optimistic scenario has 966 cells above the standard (compared to 1043 in the base case). With respect to the 120 -ppb threshold, the optimistic scenario has 117 cells above the standard (compared to 145 in the base case). Finally, at the location of highest concentration $(29,21)$, ozone is actually increased by $3 \mathrm{ppb}$ in the optimistic scenario.

\section{Overall assessment}

It may be interesting to formulate some preliminary and rough statements about the potential impacts of cool cities in these regions with the help of Table 1. It is to be understood that this statement will change (for better or worse) following the initiation of an upcoming project to be sponsored by the US EPA. Results will then be finalized once more comprehensive and accurate modeling is performed.

Table 1: Some ozone simulation statistics.

\begin{tabular}{|l|ccc||ccc||cc||c||c|}
\hline & $\mathbf{A}$ & $\mathbf{B}$ & $\mathbf{C}$ & $\mathbf{D}$ & $\mathbf{E}$ & $\mathbf{F}$ & $\mathbf{G}$ & $\mathbf{H}$ & $\mathbf{I}$ \\
\hline & $\begin{array}{l}\text { Base case } \\
>80 \mathrm{ppb}\end{array}$ & $\begin{array}{c}\text { Conservative } \\
>80 \mathrm{ppb}\end{array}$ & $\begin{array}{c}\text { Optimistic } \\
>80 \mathrm{ppb}\end{array}$ & $\begin{array}{ccccc}\text { Base case } \\
>120 \mathrm{ppb}\end{array}$ & $\begin{array}{c}\text { Conservative } \\
>120 \mathrm{ppb}\end{array}$ & $\begin{array}{c}\text { Optimistic } \\
>120 \mathrm{ppb}\end{array}$ & $\begin{array}{c}\text { Conservative } \\
\text { net change }\end{array}$ & $\begin{array}{c}\text { Optimistic } \\
\text { net change }\end{array}$ & $\begin{array}{c}\text { Optimistic } \\
\text { increase }\end{array}$ & $\begin{array}{c}\text { Optimistic } \\
\text { decrease }\end{array}$ \\
\hline Atlanta & $72 \%$ & $72 \%$ & $66 \%$ & $10 \%$ & $9.5 \%$ & $8 \%$ & $-0.1 \%$ & $-2 \%$ & 95 & 529 \\
Nashville & $43 \%$ & $43 \%$ & $42 \%$ & 0 & 0 & 0 & $-0 \%$ & $-0.4 \%$ & 58 & 294 \\
Dallas & $4 \%$ & $4 \%$ & $2 \%$ & 0 & 0 & 0 & $-0.3 \%$ & $-5 \%$ & 92 & 515 \\
\hline
\end{tabular}

In this table, field A represents the percent of cells in the modeling domain with concentrations larger than $80 \mathrm{ppb}$ in the base case at peak hour. Fields $\mathrm{B}$ and C provide same information but for the conservative and optimistic scenarios, respectively. Field $D$ represents the percent of cells in the modeling domain in the base case with concentrations larger than $120 \mathrm{ppb}$ at peak hour. Fields $\mathrm{E}$ and $\mathrm{F}$ provide similar information for the conservative and optimistic cases, respectively. The total number of cells in the analysis domain is 1444, 1672, and 1216 for Atlanta, Nashville, and Dallas, respectively.

Fields $\mathrm{G}$ and $\mathrm{H}$ give the percent net changes in mass (or concentrations) of ozone over the entire modeling domain for the conservative and optimistic cases, respectively. Finally, fields $I$ and $J$ give the number of cells in the domain with increasing and decreasing concentrations, respectively, for the optimistic scenario.

Table 1 suggests that Nashville and Dallas, during their respective simulation episodes, are in attainment with respect to the older standard, whereas Atlanta is in non-compliance. However, with respect to the newer standard, all three regions are in exceedance. The table also suggests that the conservative scenario 
has very small impacts on air quality (net decreases of less than $0.3 \%$ in concentrations) and indeed no impact with respect to the older or newer standards (see column B with respect to column A, and column $E$ with respect to column $\mathrm{D}$ ). The optimistic scenario, on the other hand, seems to have a more detectable effect. With respect to the older standard, this scenario can decrease the exceedance area in Atlanta (at 5 $\mathrm{pm}$ ) from $10 \%$ of the modeling domain down to $8 \%$ (compare columns $\mathrm{D}$ and $\mathrm{F}$ ). With respect to the 80-ppb threshold, this scenario can bring the exceedance area in Atlanta from $72 \%$ down to $66 \%$ (Columns $\mathrm{A}$ and $\mathrm{C}$ ). The table also suggests that the net change in ozone (concentrations or mass) is a decrease of $2 \%$ in the optimistic scenario (Column $\mathrm{H}$ ). The ratio of improving grid cells to deteriorating ones in Atlanta is about 5.56 to 1 (Columns I and J), which is significant.

For Nashville, the effects of cool cities seem to be the smallest. The optimistic scenario reduces the exceedance area only from $43 \%$ down to $42 \%$ (columns $\mathrm{A}$ and $\mathrm{C}$ ) and causes a net change of up to $-0.4 \%$ in ozone mass (column $\mathrm{H}$ ). The ratio of improving to deteriorating cells is 5 to 1 , still encouraging, but the magnitude of the change is very small (a few ppb in each cell).

Finally, the Dallas region seems to benefit the most from cool cities according to the preliminary modeling work in this paper. The exceedance area is brought down from $4 \%$ to $2 \%$ due to the optimistic scenario (Columns $A$ and $C$ ), and the net change over the entire domain is a decrease of $5 \%$ in concentrations (or mass, equivalently, as seen in column $\mathrm{H}$ ). The ratio of improving to deteriorating area is 5.6 to 1 .

Thus, it appears, while the areal extent of the cool cities impact may be significant, the intensity of the effect is small in Nashville, but more significant in Atlanta and Dallas - Ft. Worth. In addition, the overall picture presented in this paper may not be faithful since it lacks information on population exposure to ozone. This insightful index, will be reintroduced in the project's next phase. Finally, Table 2 recaps the earlier discussion of the impacts during peak hours.

Table 2: Impacts during peak hours.

\begin{tabular}{|l|c|cc|cc|}
\hline & $\begin{array}{c}\text { Base-case } \\
\text { highest concentration } \\
\text { at peak hour } \\
(\mathrm{ppb})\end{array}$ & $\begin{array}{c}\text { Conservative } \\
\text { largest increase } \\
(\mathrm{ppb})\end{array}$ & $\begin{array}{c}\text { largest decrease } \\
(\mathrm{ppb})\end{array}$ & $\begin{array}{c}\text { Optimistic } \\
\text { largest increase largest decrease } \\
(\mathrm{ppb})\end{array}$ \\
\hline Nashville TN & 106 & 2 & 1 & 5 & 6 \\
Dallas TX & 93 & 1 & 5 & 4 & 15 \\
Atlanta GA & 140 & 3 & 5 & 6 & 12 \\
\hline
\end{tabular}




\section{CONCLUSIONS}

This paper discussed the extension of cool cities modeling to three new regions: Atlanta GA, Dallas-Ft. Worth TX, and Nashville TN. The purpose was to assess the air quality impacts of these strategies through mesoscale meteorological and photochemical modeling. This modeling work suggests a range of possible impacts of increased albedo and urban forests both on meteorological and air quality conditions. For example, peak ozone concentrations during each region's respective episode could be decreased by 1-6 ppb (conservative and optimistic scenarios, respectively) in Nashville, 5-15 ppb in Dallas - Fort Worth, and by $5-12 \mathrm{ppb}$ in Atlanta. The reductions are generally smaller than those simulated for the Los Angeles Basin but are still significant. In all regions, the simulations suggest, the net, domain-wide effect of cool cities is a reduction in ozone.

The modeling results also suggest that while the areal extent of cool cities impacts may be significant, the intensity of the effect is small in Nashville, but more important in Atlanta and Dallas - Ft. Worth, with Dallas apparently benefiting the most from cool cities strategies. In Dallas, Atlanta, and Nashville, net domain-wide changes in ozone concentrations amount to $-5 \%,-2 \%$, and $-0.4 \%$, respectively, in the optimistic cool cities scenario.

The results are to be taken as preliminary and exploratory and will likely change during a more comprehensive modeling project to be initiated soon with the support of the US Environmental Protection Agency. In the upcoming modeling study of these (and other) regions, another important index missing from this paper will be introduced. This is the population-weighted exposure above various concentration thresholds. This index will give a more powerful and more accurate representation of the possible impacts of cool cities on air quality in several US regions. 


\section{REFERENCES}

Akbari, H., Bretz, S., Kum, D., and Hanford, J. 1994. "Peak power and cooling energy savings of highalbedo roofs". Accepted for publication in Energy and Buildings - Special Issue on Urban Heat Islands and Cool Communities.

Cardelino, C.A. and Chameides, W.L. 1990. "Natural hydrocarbons, urbanization, and urban ozone", Journal of Geophysical Research, Vol. 95, No. D9, pp. 13971-13979.

EPA 1986. "Guideline on Air Quality Models (Revised)". U.S. Environmental Protection Agency EPA-450/2-78-027R.

Gabersek, S. and Taha, H. "Impacts of surface characteristics changes on urban heat island intensity". ICB 96, 14th International Congress of Biometeorology, September 1-8, 1996, Ljubljana, Slovenia.

Gery, M.W., Whitten, G.Z., Killus, J.P. 1988. "Development and testing of the CBM-IV for urban and regional modeling", Report EPA-600/3-88-012, U.S. EPA, Research Triangle Park, NC.

Parker, D.S. and Barkaszi, S.F. 1994. "Roof solar reflectance and cooling energy use: Field research results from Florida", Accepted for publication in Energy and Buildings - Special Issue on Urban Heat Islands and Cool Communities.

Pielke, R. 1974. "A three-dimensional numerical model of the sea breeze over South Florida", Monthly Weather Review, 102:115-139.

Sailor, D. 1993. "Role of surface characteristics in urban meteorology and air quality", Ph.D. dissertation, University of California - Berkeley.

Simpson, J.R. and McPherson, E.G. 1993. "The effects of roof albedo modification on cooling loads of scale model residences in Tucson, Arizona", Accepted for publication in Energy and Buildings - Special Issue on Urban Heat Islands and Cool Communities.

Taha, H. 1997. "Modeling the Impacts of Large-Scale Albedo Changes on Ozone Air Quality in the South Coast Air Basin", Atmospheric Environment, Vol. 31, No. 11, pp. 1667-1676 (1997). 
Taha, H., Konopacki, S., and Akbari, H. 1997a. "Impacts of lowered urban air temperatures on precursor emission and ozone air quality", Accepted for publication in The Journal of the Air \& Waste Management Association.

Taha, H., Douglas, S., and Haney, J. 1997b. "Mesoscale meteorological and air quality impacts of increased urban albedo and vegetation", Energy \& Buildings - Special Issue on Urban Heat Islands, Volume 25, Number 2 (1997), pp. 169-177.

Taha, H. 1996. "Modeling the Impacts of Increased Urban Vegetation on the Ozone Air Quality in the South Coast Air Basin", Atmospheric Environment, Vol. 30, No. 20 (1996), pp. 3423-3430.

Taha, H., Liu, X., Sailor, D., Meier, A., Benjamin, M., Bloch, L., Winer, A., Douglas, S., and Haney, J., 1994. "Analysis of Energy Efficiency and Air Quality in the SoCAB - Phase II Report", Lawrence Berkeley National Laboratory Report No. LBNL-35728, Berkeley, California.

Tran, K.T. and Mirabella, V.A. 1997. "Meteorological and photochemical modeling of large-scale albedo changes in the South Coast Air Basin", Unpublished Report, Applied Modeling Incorporated, Woodland Hills, California.

\section{ACKNOWLEDGMENTS}

The author acknowledges the developers of PAVE (Package for Analysis and Visualization of Environmental data) at MCNC in North Carolina for making the software freely available for use in visualization of UAM output such as in this study. Dr. Gerrit Hoogenboom and Ms. Dee Dee Gresham are acknowledged for providing mesonet meteorological data from stations throughout the State of Georgia that were used in validating the model simulations of Atlanta GA, and testing the base-case performance in this paper. Drs. Larry Gautney of TVA, Michael Chang of GIT/GDNR, and David Jacob of TNRCC are acknowledged for providing emission inventories for the modeling domains of Nashville TN, Atlanta GA, and Dallas TX, respectively. Their assistance is very much appreciated.

Thanks to Dr. Hashem Akbari, leader of the Heat Island Project at the Berkeley Laboratory and Mr. Marc Decot, Project Manager at the US DOE for their support and guidance. This work was sponsored by the United States Department of Energy under Contract DE-AC03-76SF00098. 


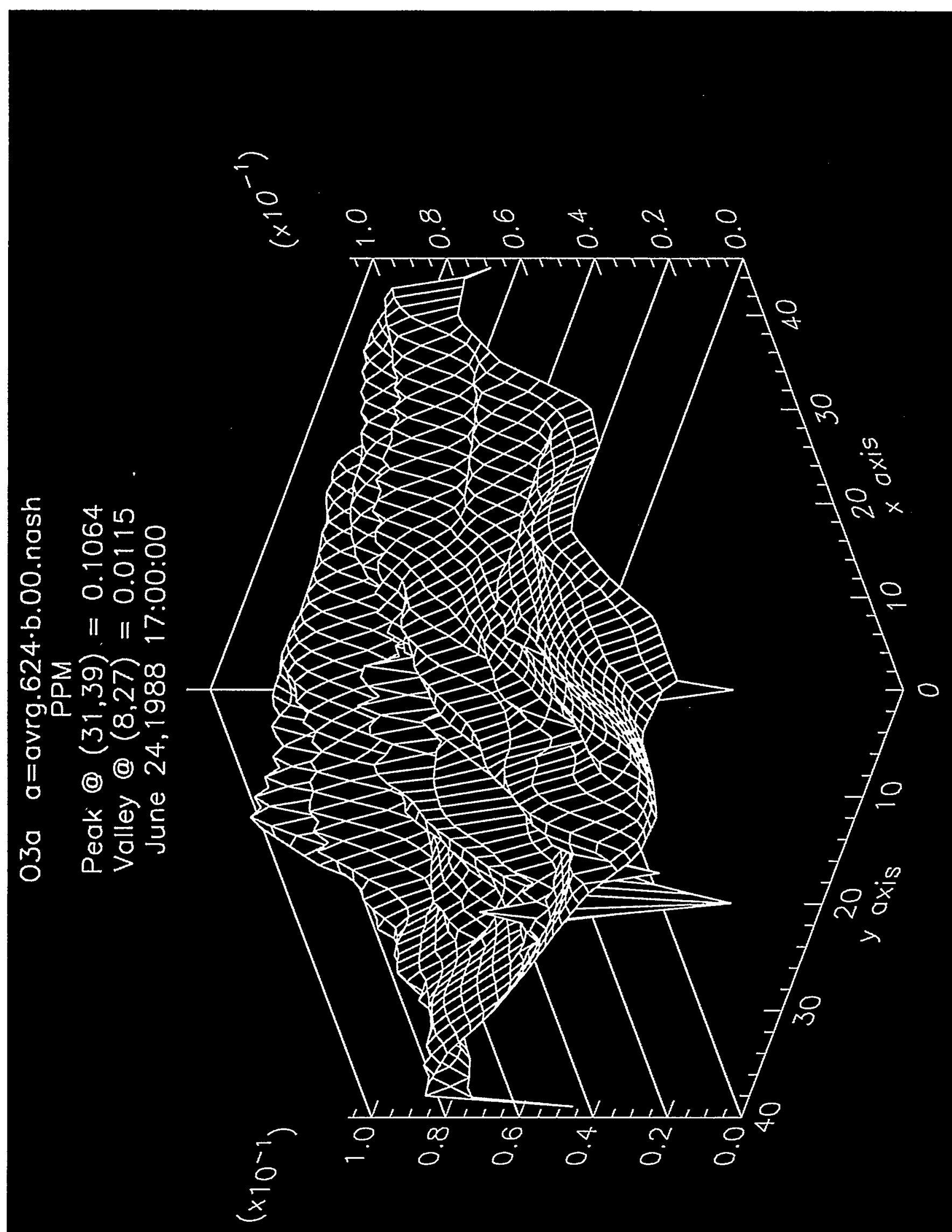




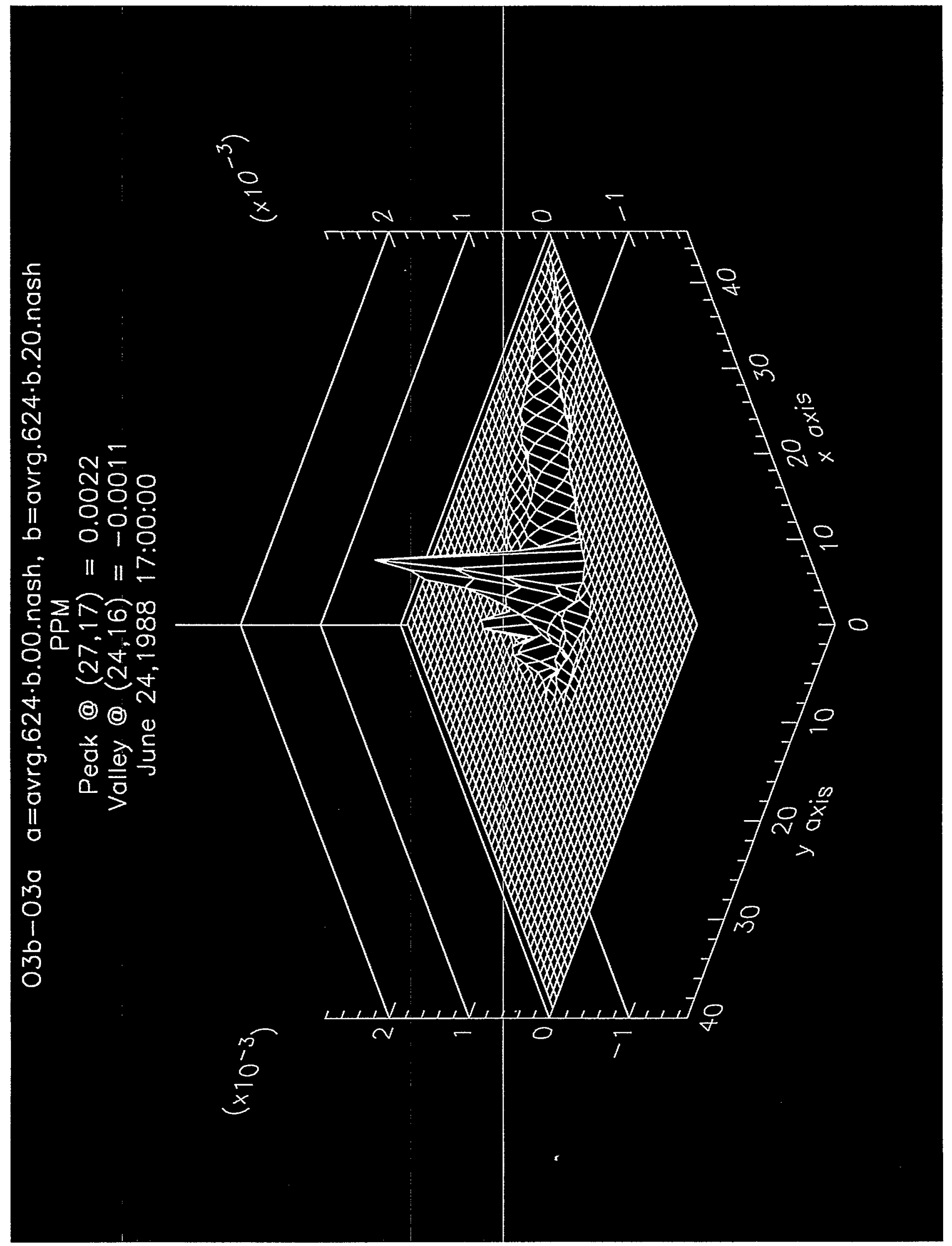




$$
\begin{gathered}
\text { 03h-03a } a=\text { avrg.624.b.00.nash, } h=\text { avrg.624.b.a6 } \\
\text { PPM } \\
\text { Peak @ }(31,17)=0.0053 \\
\text { Valley @ }(29,23)=-0.0061 \\
\text { June } 24,198817: 00: 00
\end{gathered}
$$

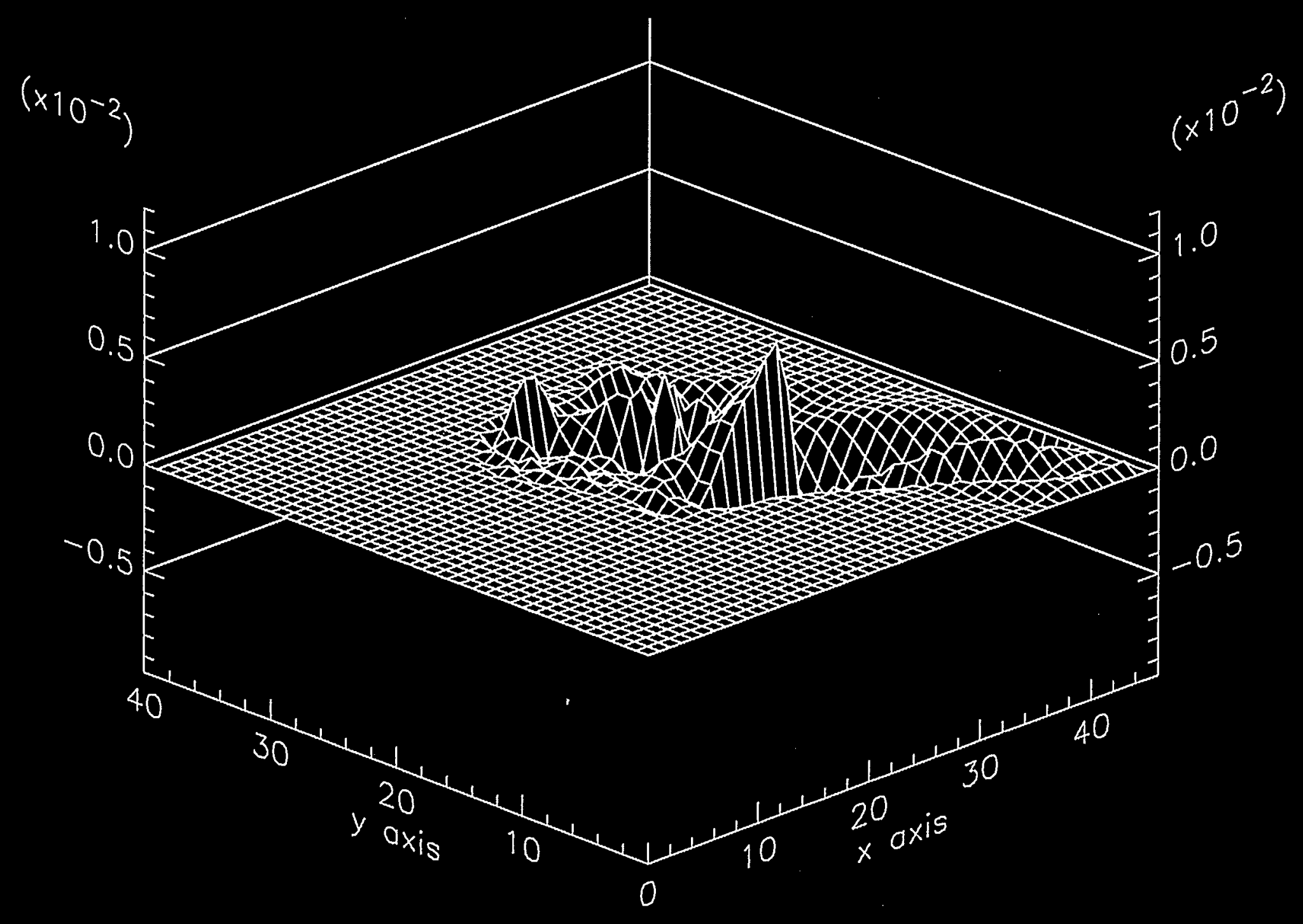

Figure 3. Modified conditions in Nashville Tli (optimistic). 


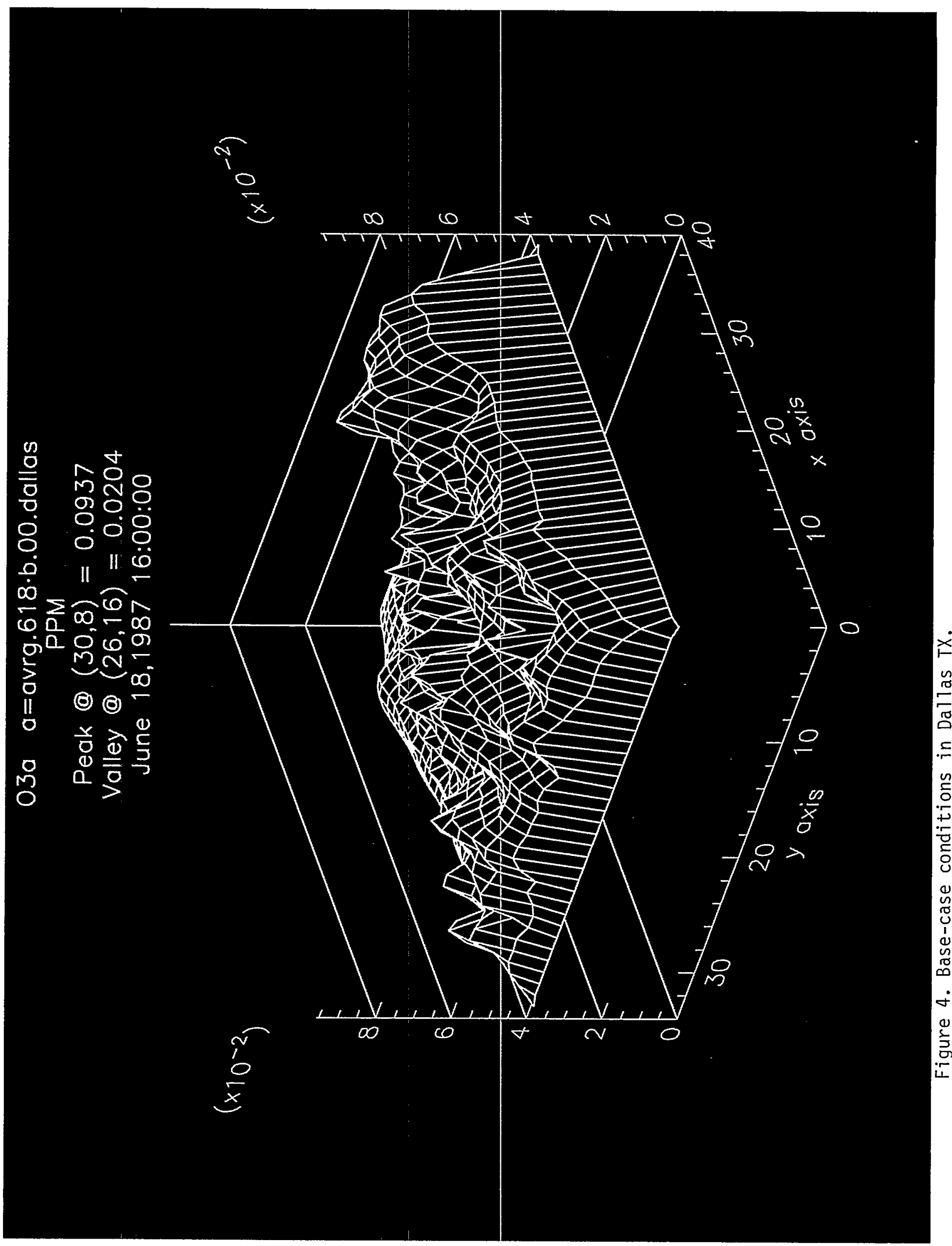



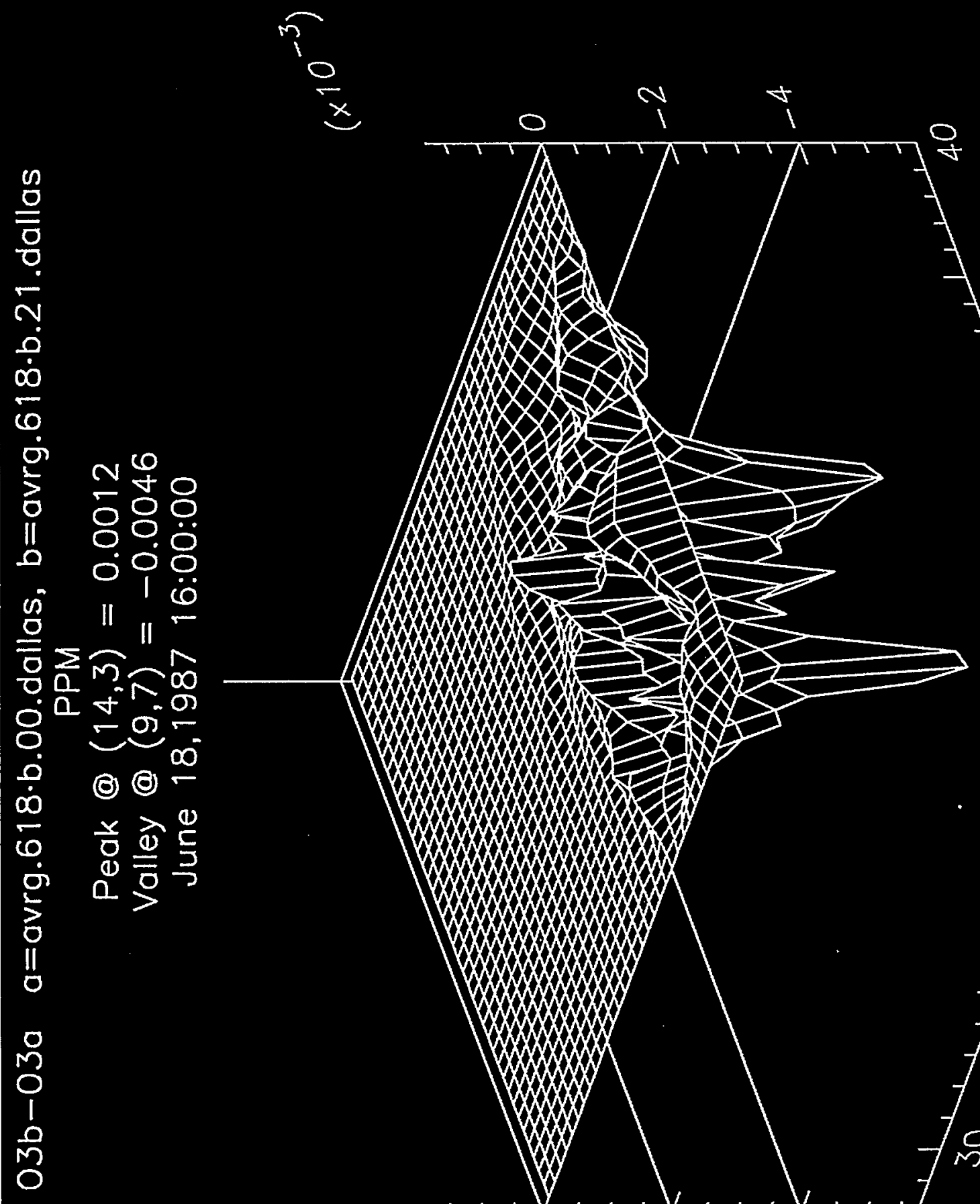

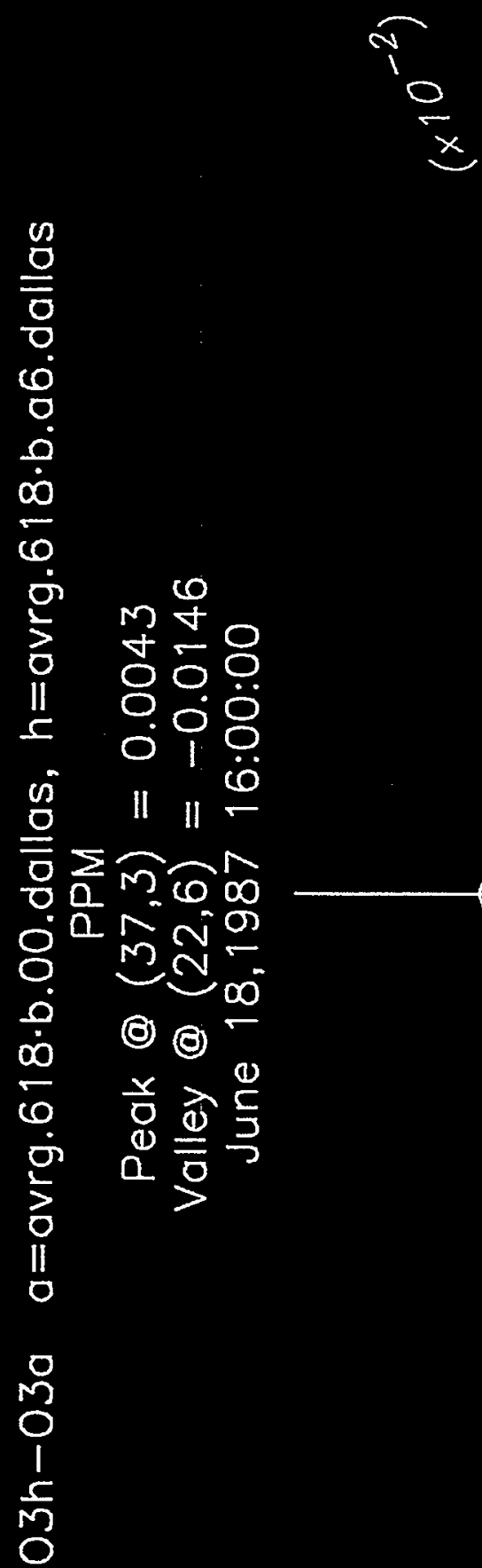


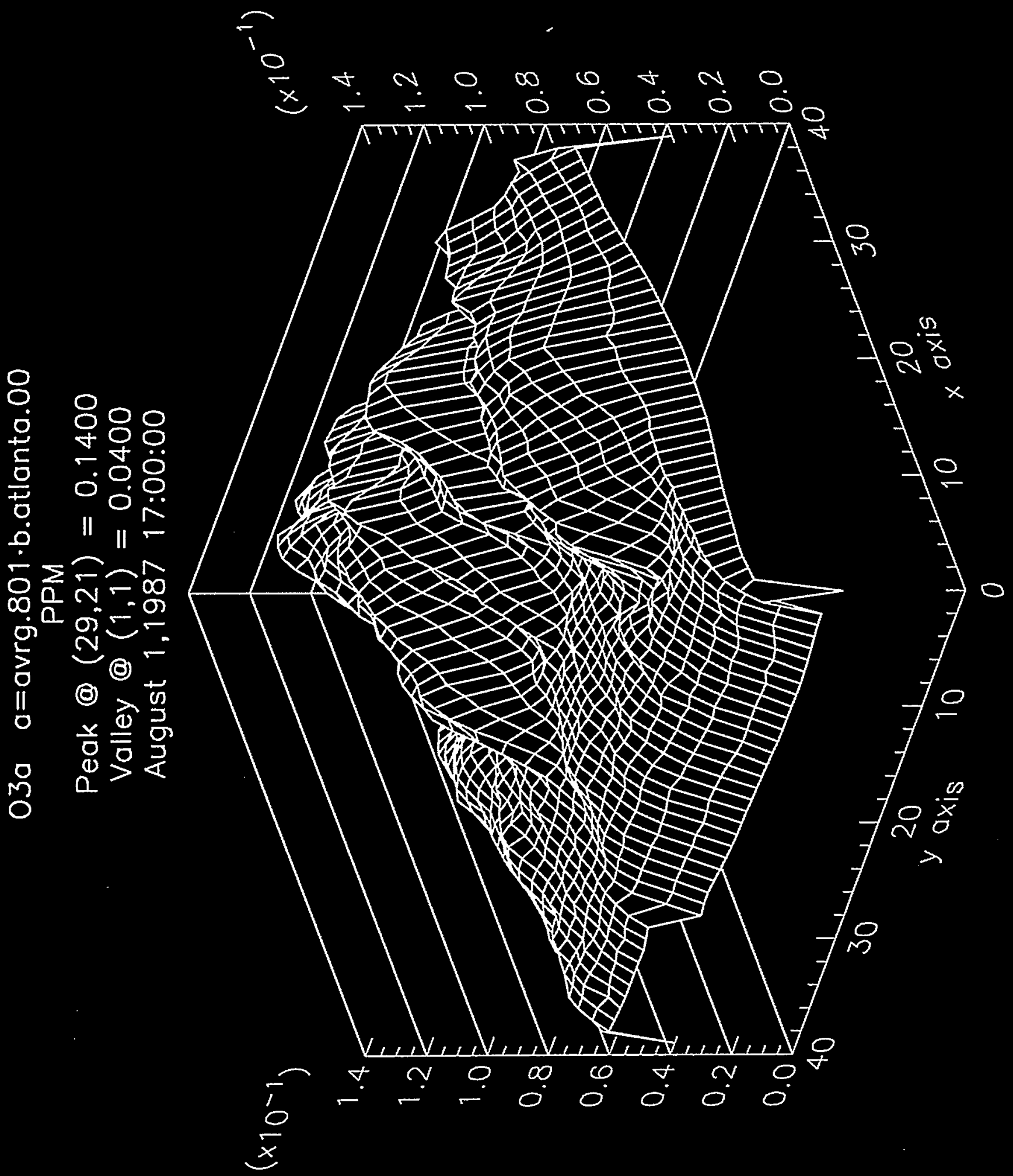




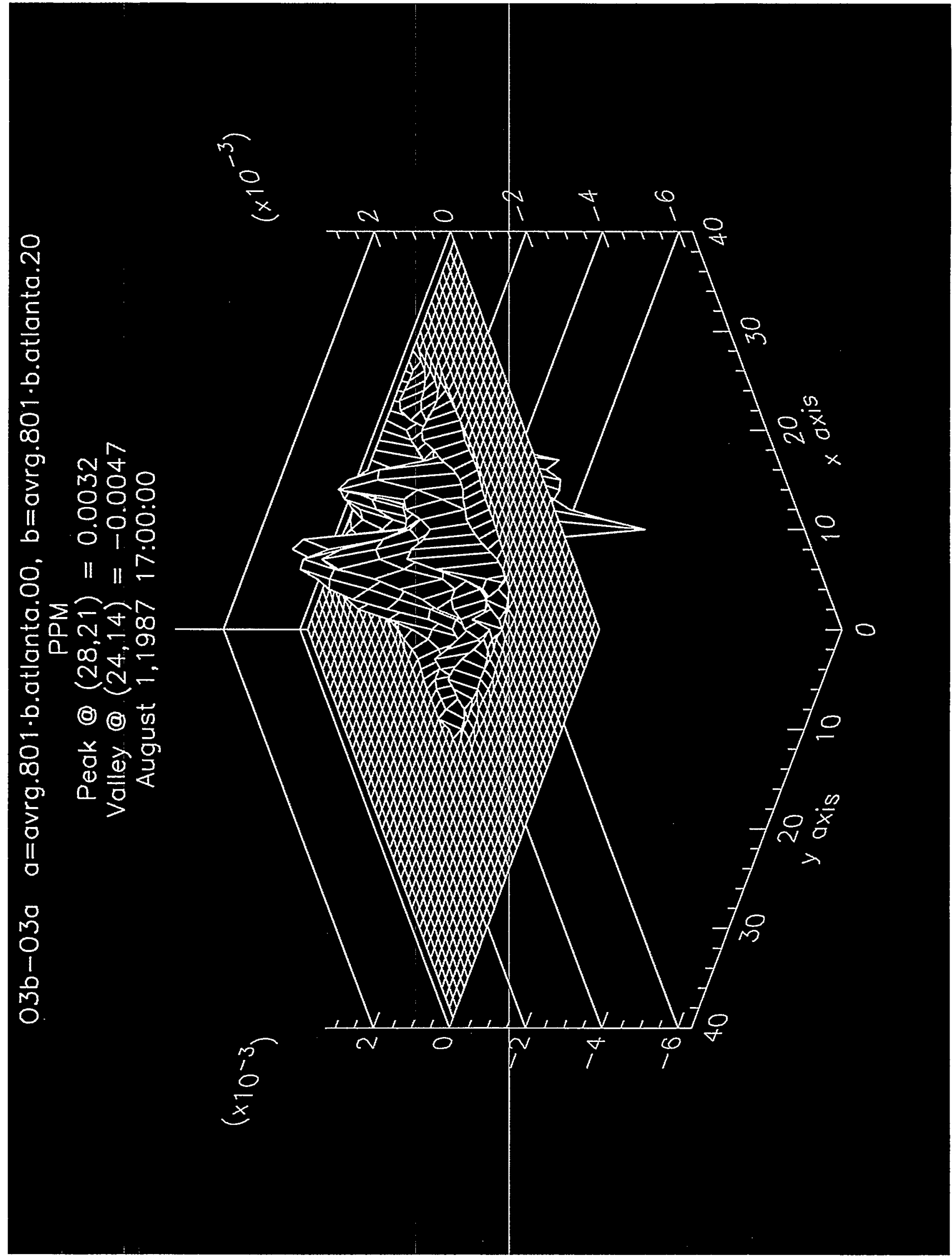




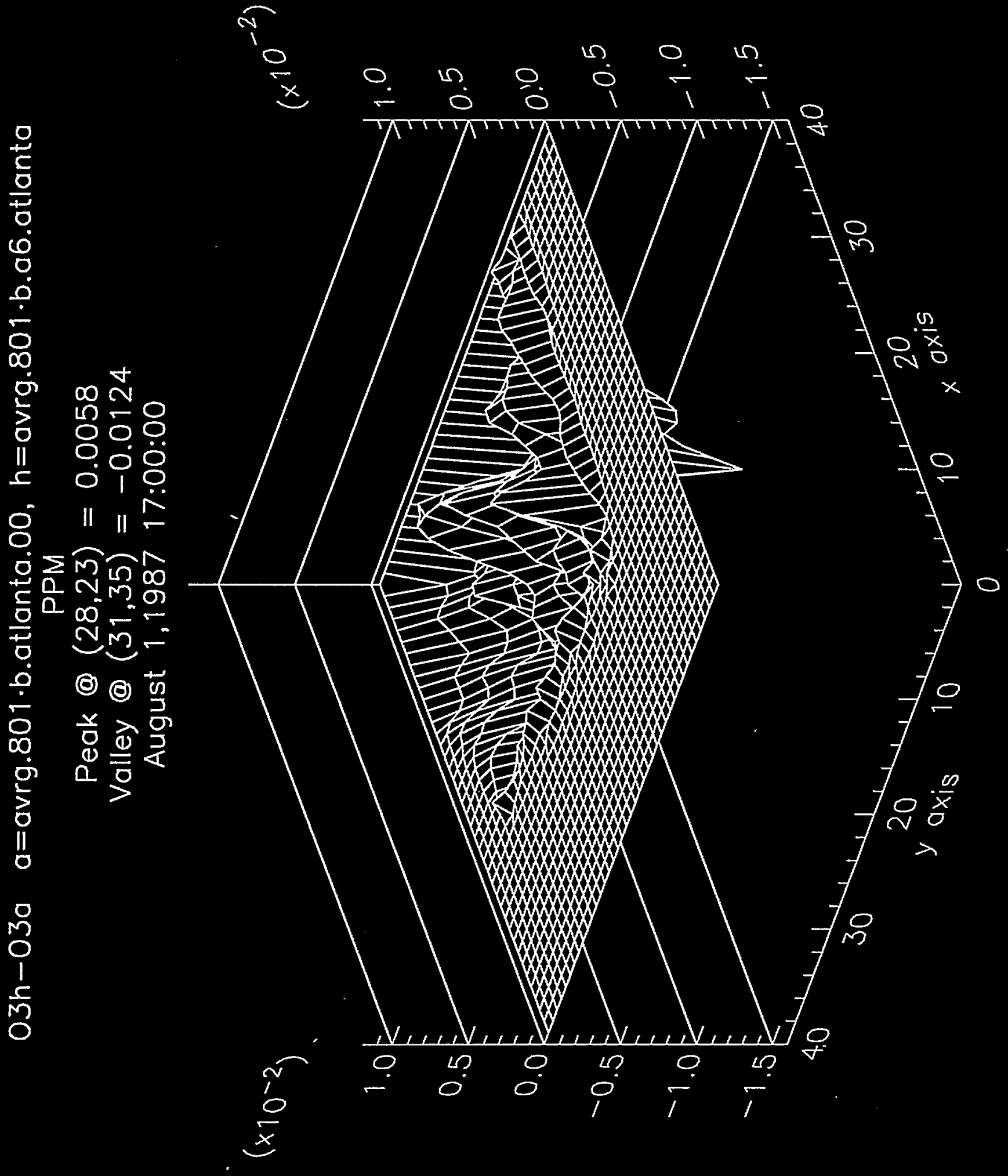

